\title{
Obtaining cyclopentanone from acidic wastewater of caprolactam production
}

\author{
I. V. Tsvetkova ${ }^{*}$ A. A. Golovanov, \\ N.S. Reznikova, N. V. Chirkunova \\ Togliatti State University, 14 Belorusskaya st., \\ Tolyatti, Samara region, 445020, Russia \\ "email: irina.cvetkova.56@mail.ru
}

\begin{abstract}
It has been shown that adipic acid released from the by-products of caprolactam production is a promising raw material for the production of cyclopentanone. The thermal stability of calcium adipate was investigated by the derivatographic method and the conditions were selected that ensure the yield of at least $50 \%$ of the target cyclopentanone with a purity of at least $99 \%$.
\end{abstract}

Keywords: wastes from caprolactam production; adipic acid; cyclopentanone; derivatography; calcium adipate; gas chromatography

Received: 22.10.2020. Accepted: 08.12.2020. Published:30.12.2020.

(c) Tsvetkova I. V., Golovanov A. A., Reznikova N. S., Chirkunova N. V., 2020

\section{Results and discussion}

The process of oxidation of cyclohexane with oxygen from air, carried out in the production of caprolactam as a separate step is characterized by a large amount of oxygen-containing side-products concentrated in acidic wastewater. One of these compounds is adipic acid [1].

The adipic acid is converted to a calcium salt, and the calcium salt decomposes to cyclopentanone during the high-temperature treatment (Fig. 1). Cyclopentanone is an important intermediate in the production of insecticides, pharmaceuticals, and fragrance chemistry (synthesis of jasmon). In the pharmaceutical industry,

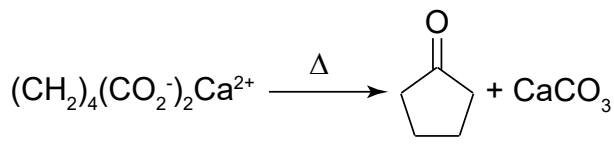

Fig. 1. Decomposition reaction of calcium adipate cyclopentanone is a precursor in the production of cyclopentobarbital, a sedative barbiturate derivative. Cyclopentanone is also used to produce cyclopentamine, which is an intermediate in the synthesis of fungicides such as pencycuron [2].

The solid concentrate of acidic wastewater was methylated with diazomethane to obtain methyl esters of carboxylic acids. The analysis of the methylated products was carried out on a Kristallux 4000M chromatograph with a flame ionization detector (capillary column, helium carrier gas, quartz, DB-WAX (PEG), $30 \mathrm{~m} /$ $0.32 \mathrm{~mm} / 0.5 \mu \mathrm{m}$, maximum thermostat temperature is $240{ }^{\circ} \mathrm{C}$ ) showed that the solid residue of the acidic wastewater from the production of caprolactam contains up to $94 \%$ of adipic acid (Fig. 3).

Calcium adipate was synthesized from the resulting product. The thermal stability 
of the calcium adipate was studied on a Shimadzu DTG-60/60H thermal analyzer, and the initial temperature of its decomposition was determined as $400{ }^{\circ} \mathrm{C}$. The thermal effect of the decomposition reaction is $5.68 \mathrm{~kJ} / \mathrm{g}$ (Fig. 3).

The pyrolysis of calcium adipate in a quartz reactor was carried out, and the yield of cyclopentanone was calculated as $51 \%$.

The resulting product was subjected to chromatographic analysis. The retention time of the technical sample of cyclopen- tanone (96.4\% purity) is 6.24 minutes versus 6.20 minutes for the standard sample of cyclopentanone of $99.6 \%$ purity. The difference in the retention times of the standard sample (Fig. 4) and the technical one (Fig. 5) may be due to the presence of impurities in the second one.

As a result, the possibility of obtaining cyclopentanone from by-products of caprolactam production with good yield and high concentration in liquid products has been shown.

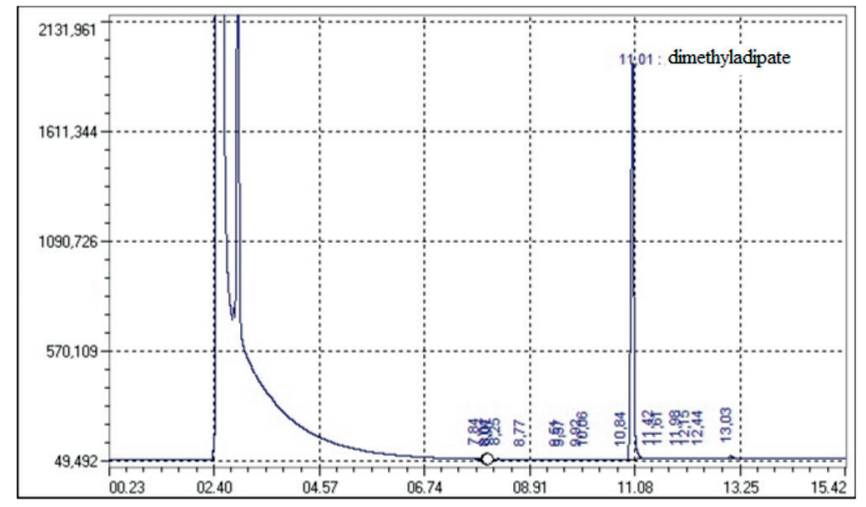

Fig. 2. Chromatogram of the content of dimethyladipate in methylation products

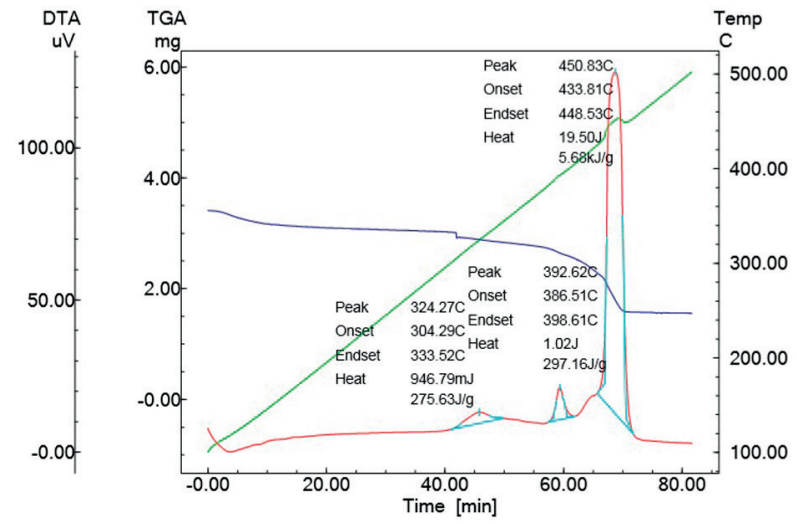

Fig. 3. The derivatogram of calcium adipate 


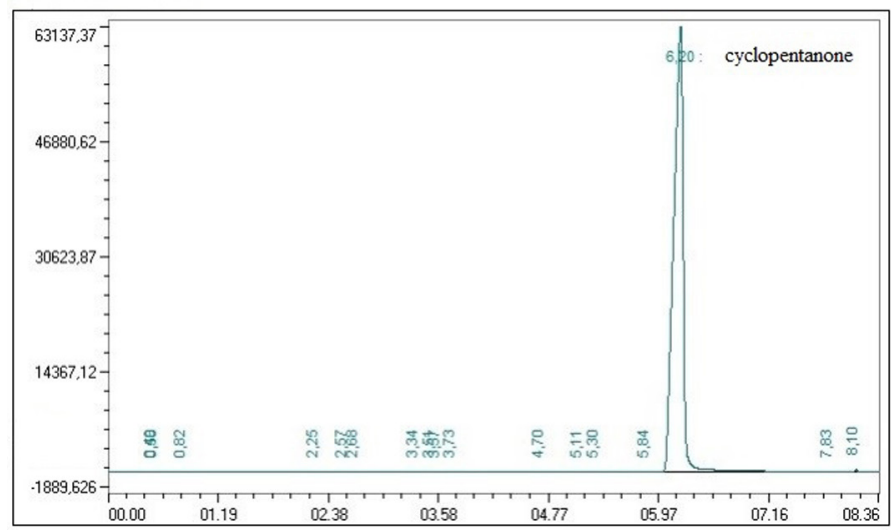

Fig. 4. Chromatogram of the standard sample of cyclopentanone

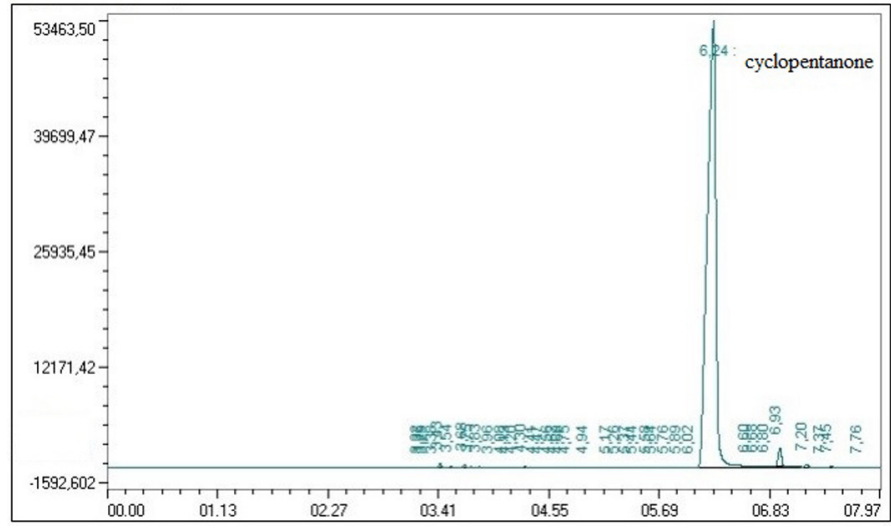

Fig. 5. Chromatogram of the technical sample of cyclopentanone

\section{References}

1. Kisil IM, Preobrazhensky VA, Zolin VS, Gorodetskaya NI, Davydov YuI, Polikarpov AV, Salomykov VI. Method of utilization of acidic wastewater of caprolactam production: Pat. 2039740 Rus. Federation. 93009600/04; declared 02.24.1993; publ. 07.20.1995

2. Carbonyl compounds in the synthesis of heterocycles: K82 Coll. scientific. tr. / Ed. prof. A. P. Krivenko. Saratov: Publishing house "Scientific book", 2008. 324 p. 